\title{
Analysis on the Influence Factors of Wind Power Accommodation
}

\author{
Xiaofei Li1', Yuehui Huang1, Shuo Ma1, Changjun Li², Xiaolei Ma² \\ ${ }^{1}$ Renewable Energy Department, China Electric Power Research Institute, Beijing, China \\ ${ }^{2}$ State Grid Xinjiang Electric Power Corporation, Wulumuqi, China \\ Email: lixiaofei3@epri.sgcc.com.cn
}

Received January 2015

\begin{abstract}
With the increase of wind power capacity in China, the situation of curtailment of wind power is getting worse. An annual sequence production simulation model is established with maximum wind power consumption as the objective function. The calculation of specific power grid operation in 2013 verifies the precision of this model. The impact of different factors on wind power accommodation as well as the impact of power grid reserve, wind resources and load on wind power curtailment is analyzed. The calculation results quantify the impact of different factors from power system to the accommodation of wind power and provide reference to solving the problem of wind power curtailment.
\end{abstract}

\section{Keywords}

Wind Power Accommodation, Time Sequence Simulation, Spinning Reserve

\section{Introduction}

In 2014, the newly installed wind power capacity in China (excluding Taiwan) is 18.6 GW, the total installed wind power capacity is up to $95.8 \mathrm{GW}$, a year-on-year growth of $24.2 \%$, as shown in Figure 1. Wind power is mainly distributed in the "Three North" areas in China. Wind power capacity in North China, Northeast China and Northwest China accounts for 13\%, 20\% and 12\% respectively of the total installed capacity and wind power accounts for more than $30 \%$ in some provinces [1]. According to the wind power development planning in China, the national wind power capacity will reach 104 GW in 2015 and 200 GW in 2020.

Affected by the distribution of wind resources, wind power generation is developed in a large-scale and centralized way in China. More than $90 \%$ of wind distribution is in the "Three North" areas where power supply mainly depends on coal-fired thermal power units. The regulation ability of thermal power is insufficient and unit commitment is not flexible. Because the output of wind power is volatile and uncertain, it's difficult for conventional thermal power units, limited by peak-load regulation capacity to satisfy the requirement of large scale wind power for peak regulation, frequency modulation and so on, which leads to frequent wind power curtailment in China's "Three North" areas in recent years. Power grid peak-load regulation capacity shortage has become the main factors that hinder the further development of wind power in some area [2]. Relevant sta- 


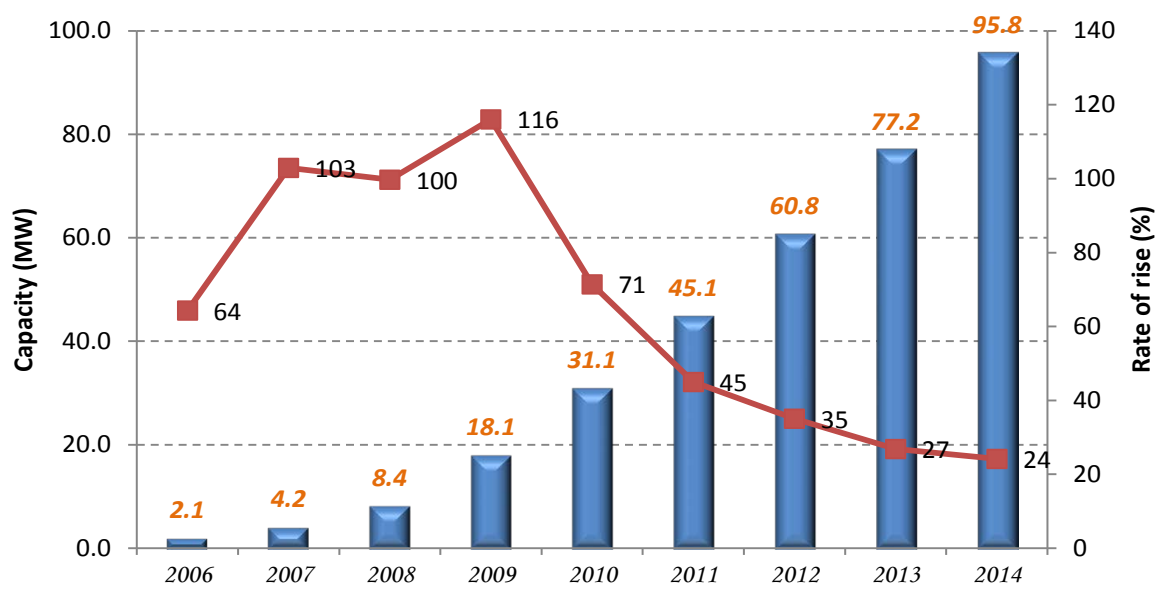

Figure 1. Wind power capacity and increase rate over the years of China.

tistic shows that the curtailment of wind power in 2011, 2012 and 2013 was up to 10 TWh, 20 TWh and 16.2 TWh respectively. Therefore, further research on power grid peak-load regulation capacity of and its impact on wind power accommodation is significantly important to the wind power development of China.

\section{Analysis of Influence Factors of Wind Power Accommodation}

As can be seen from the current wind power operation experience in wind power curtailment area of China, the influencing factors of wind power accommodation is mainly divided into two kinds: one is the peak-load regulation capacity of power grid, the other is grid transmission capacity [3]. The influence factors of peak-load regulation capacity includes power load characteristics, power unit boot mode, spinning reserve capacity, power unit peak-load capability and pumped storage capacity, as shown in Figure 2.

Curtailment of wind power due to both peak-load regulation of power grid and transmission capacity restriction, when transmission capacity restriction is released, curtailment power caused by it may be transformed into the other type caused by peaking capacity, as shown in Figure 3. In current curtailment statistical mode, transmission capacity restriction is indicated as Section 2 and Section 3 [4]; peak-load regulation capacity is indicated as Section 1. But the real situation should be transmission capacity restriction in Section 2 and peak-load regulation capacity in Section 1 and Section 3 which indicates the part transformed from transmission capacity restriction. Taking a provincial power grid as an example, in current statistical mode, curtailment from transmission capacity restriction accounts for $60 \%$, but in reality it should account for $40 \%$, the problem of peak-load regulation capacity of power grid is more serious.

Thermal power units' commitment in China is currently arranged by way of planning, with load forecasting for next day, reserve capacity of system and tie line plan taken into consideration. Thermal power units' commitment is also limited by the minimum unit mode stipulated by electric power supervision department power regulation authorities plan. Minimum unit mode is adopted mainly because of winter heating and power plant building insulation requirements. Limited by the minimum operation mode in thermal power, peak-load regulation capacity of power grid is significantly lower in the winter heating period. The following Table 1 shows minimum number of thermal power unit and minimum output in heating period and non-heating period in North China [5].

\section{Analysis of Optimization Model}

In this paper, a power grid model was established based on the power balance of the whole grid to calculate wind power consumption, with full consideration of spinning reserve, output range of thermal power and other restrictions.

\subsection{Object Function}

The objective function of the time sequential production simulation is maximum consumption of wind power, 


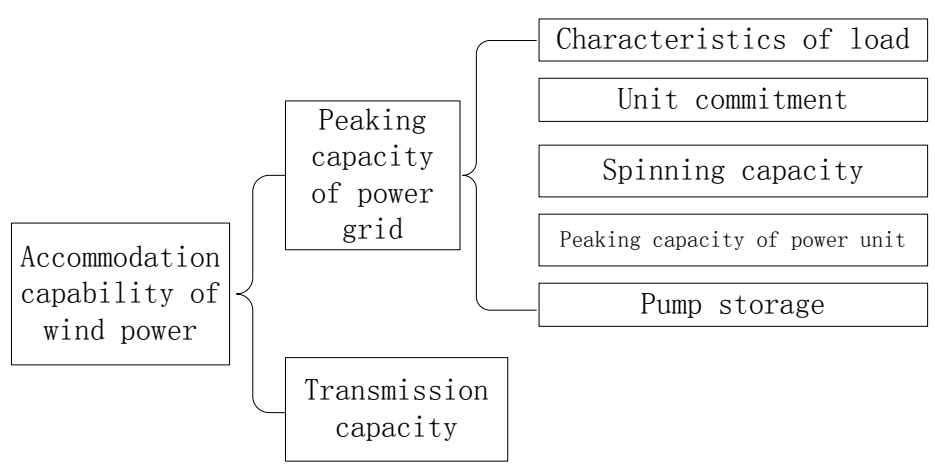

Figure 2. The influence factors of wind power accommodation.

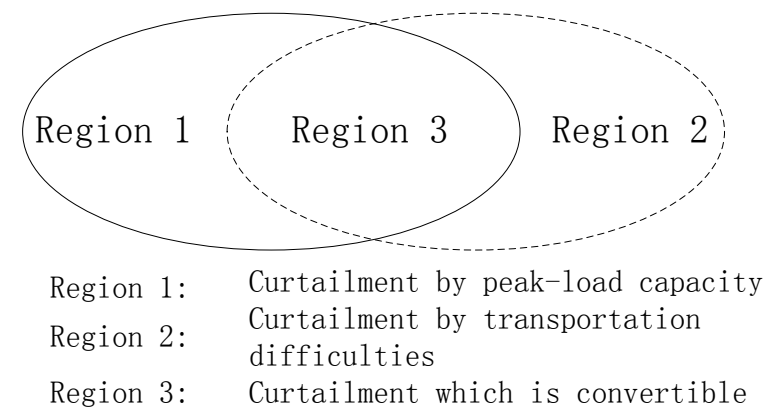

Figure 3. The relationship between peak-load regulation capacity of power grid and transmission capacity restriction.

Table 1. The operation situation of thermal power in North China.

\begin{tabular}{ccc}
\hline Period & The minimum number of thermal power & The minimum output of thermal power (\%) \\
\hline Non-heating period & 32 & 58 \\
Initial and end of heating period & 47 & 64 \\
Middle of heating period & 55 & 66 \\
\hline
\end{tabular}

namely, total maximum wind power of each region in different periods, as shown in Equation (1).

$$
\max \sum_{t=1}^{T} \sum_{n=1}^{N} P(t, n)
$$

Among them, $N$ is the number of partitions of the power grid; $T$ is the calculation step, for 1 hours; $P(t, n)$ is wind power of the $n$ partition in the $t$ period [6].

\subsection{Balance of Electric Power and Energy}

$$
\sum_{i=1}^{N} p_{i}(t)+\operatorname{TieP}(t)=L(t), \quad t=1,2, \cdots, T
$$

In Equation (2), $\quad p_{i}(t)$ is the unit $i$ output at time $t ; N$ is the number of unit (include wind power); TieP( $t$ ) is the tie line power at time $t$ (input is positive, output is negative); $L(t)$ is the whole electricity load at time $t$.

\subsection{Spinning Reserve Constraints}

In Equation (3), $S_{P}$ and $S_{N}$ are respectively positive/negative spinning reserve of power system; $C_{N}^{t}$ is the credible wind power capacity. Taking wind power into the thermal power boot program can minimize conven- 
tional unit commitment and enhance peak-load regulation capacity of power grid [7]. Spinning reserve takes the higher value of $5 \%$ of load or the largest single unit capacity.

$$
\left\{\begin{array}{l}
\sum_{j=1}^{N_{j}} P_{j}^{\max }+C_{N}^{t} \geq P_{l}^{t}+S_{P} \\
\sum_{j=1}^{N} P_{j}^{\min }+C_{N}^{t} \leq P_{l}^{t}-S_{N}
\end{array}\right.
$$

\subsection{Power Output Limit}

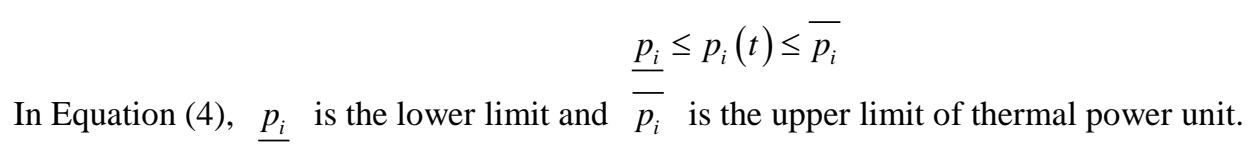

\subsection{Pumped Storage Model}

$$
p_{p}^{t} \cdot p_{h}^{t}=0
$$

In Equation (5), $p_{p}^{t}$ is the pumping condition of pumped storage unit; $p_{h}^{t}$ is the generating condition. Pumping and generating can't be conducted simultaneously [8].

\section{Calculation Verification}

\subsection{Calculation for Previous Years}

Take a provincial power grid as example and calculate its annual wind power output. The wind power operation of Power Grid A in 2013 is calculated with its wind power output sequence over different years. The calculation result is compared with the actual operation data of Power Grid A in 2013, so as to verify the precision of this model.

\subsection{Data for Calculation}

1) Load curve

Take the predictive value of load as the annual load curve for calculation. The maximum value is $24.74 \mathrm{GW}$ and the minimum value is $14.85 \mathrm{GW}$. The maximum daily peak valley difference value is $5.10 \mathrm{GW}$ and the minimum difference is $1.71 \mathrm{GW}$, as shown in Figure 4.

2) Capacity of wind power

Wind power installed sequence is total wind power installed for wind power production. Wind power installed capacity increases by steps. $1020 \mathrm{MW}$ wind power is expected to be added annually and the cumulative wind power installed capacity will reach $7.35 \mathrm{GW}$, as shown in Figure 5.

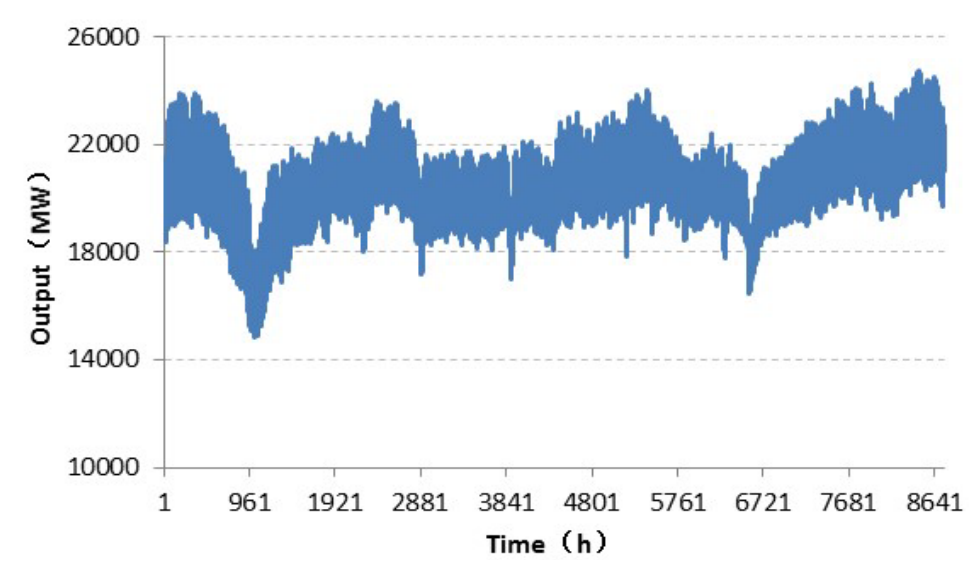

Figure 4. Annual load curve. 


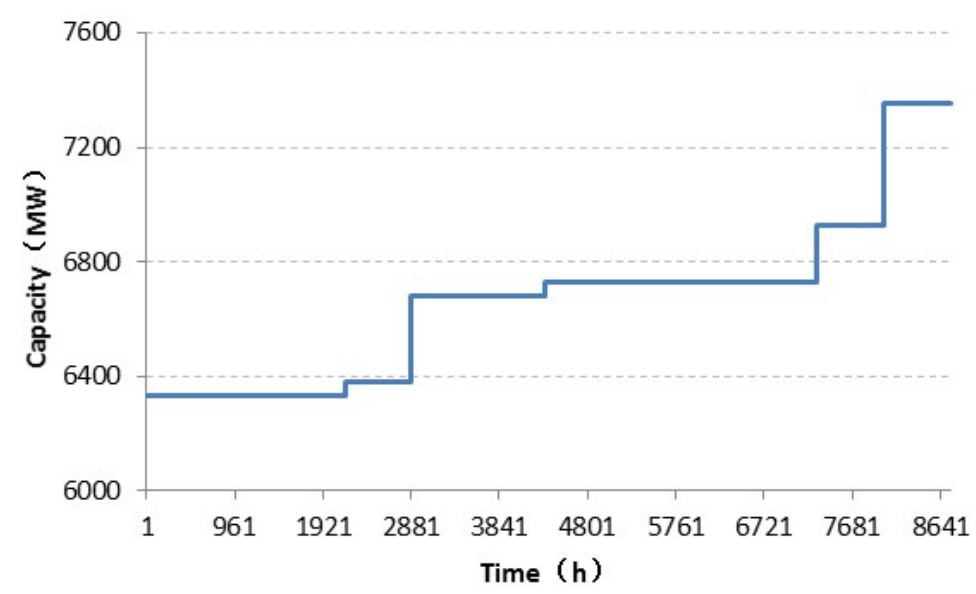

Figure 5. Installed capacity sequence of wind power.

3) Output of wind power

Wind power output data is normalized with consideration of wind power reduction. The full load hour of wind power is 2050 hours. The highest of wind power normalization is $83 \%$ and the minimum is 0 , as shown in Figure 6.

4) Peaking capacity of thermal power

Thermal power unit is mainly composed of pumping thermal unit and air condensing thermal unit. Air condensing thermal unit is not heating units and its minimum output is unchanged; pumping thermal unit generates both heat and electricity and its minimum output is different in heating period and non-heating period, as shown in Table 2.

\subsection{Calculation Results}

Calculation results are shown in Table 3. The data for 2013 is the actual operation statistics, while those for 2010, 2011, 2012 and 2014 are calculation data. The deviation between calculated output and actual power generation in 2013 is no more than 5\%, which indicates the credibility of calculation results.

\section{Analysis on Wind Power Accommodation Capacity}

This calculation model aims at maximizing wind power consumption and optimizing thermal power unit commitment and output. Because variables of the model are huge and it is a typical mixed integer programming problem, this paper adopts GAMS to solve it. The calculation results show that, on the premise of maximum accepted wind power, the whole year is expected to consume 11.6 TWh of wind power with 1.2 TWh of curtailment and the full load hours of wind power is 1675 hours.

\subsection{Impact of Spinning Reserve on Wind Power Accommodation}

Spinning reserve capacity affects the unit's boot capacity, the bigger the spinning reserve, the higher the minimum technical power and the more the wind power curtailment. When the power system spinning reserve is respectively assumed as $5 \%, 10 \%, 15 \%$ and $20 \%$, wind power accommodation conditions are detailed in Table 4 , the wind power generation quantity decreases while the wind power curtailment and its proportion increase.

\subsection{Impact of Wind Resources on Wind Power Curtailment}

Wind power curtailment varies between power grids with different wind resources, that is, more wind resources lead to higher curtailment rate fewer wind power resources lead to lower curtailment rate. And the influence degree varies between different provinces and regions (A1 to A6), as can be seen in Figure 7, where A1 and A6, with curtailment rates standing at $4.6 \%$ and $6.0 \%$ respectively, are influenced more by wind resources than A2 and A3 whose curtailment rates are both $1.2 \%$. 


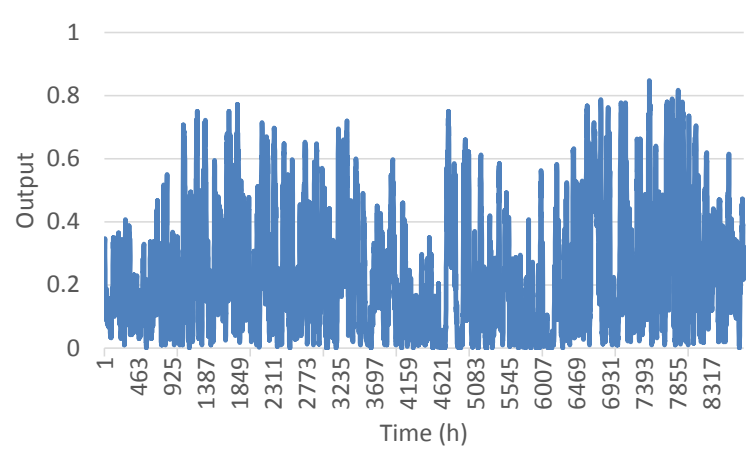

(a)

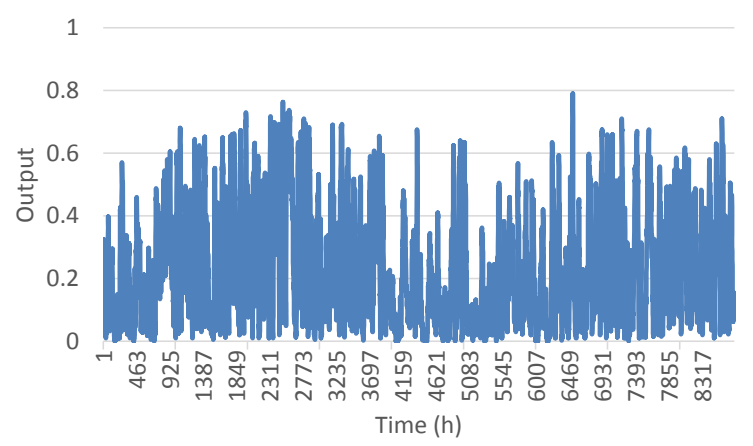

(c)

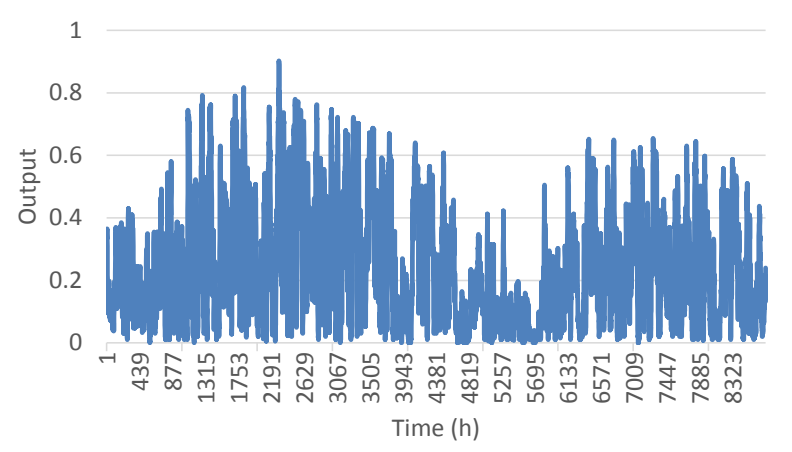

(b)

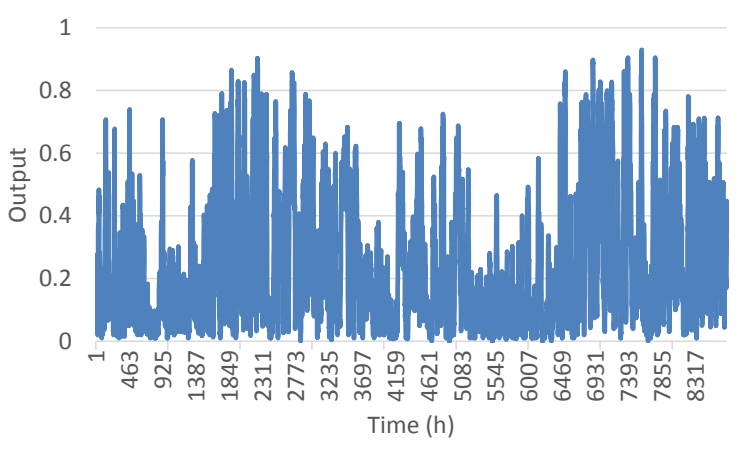

(d)

Figure 6. Normalization output sequence of wind power in different years.

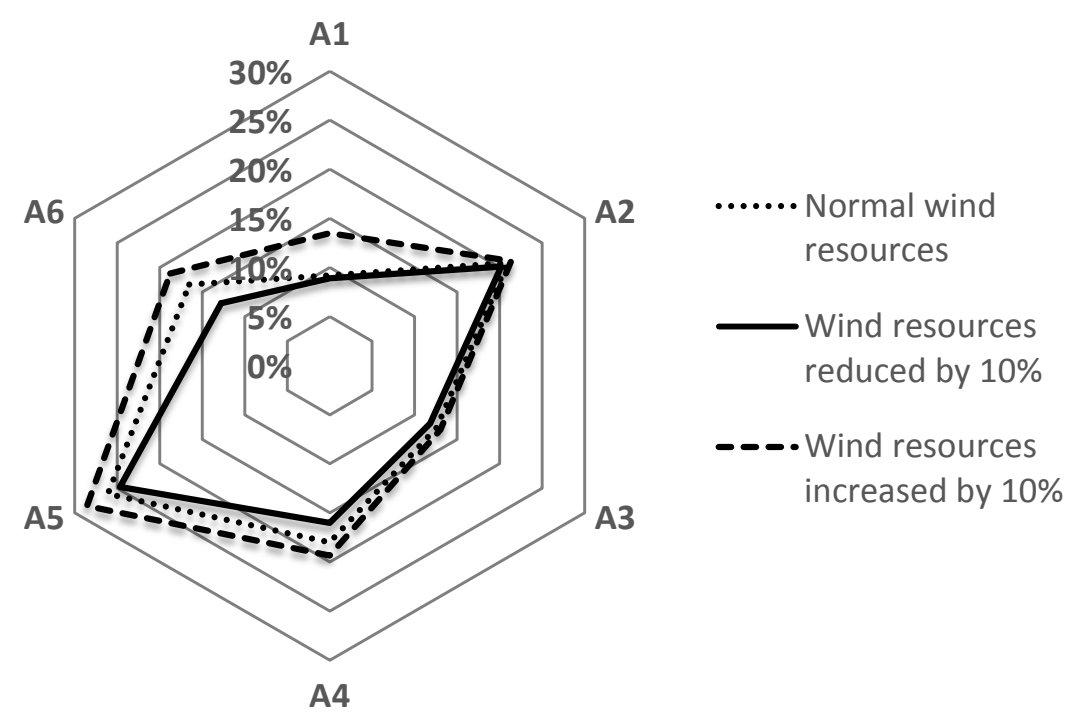

Figure 7. Influence of wind resources on wind power curtailment.

\subsection{Impact of Load on Wind Power Curtailment}

Wind power curtailment varies between power grids with different load capacity, that is, lower load leads to higher curtailment rate while higher load leads to lower curtailment rate. And load influence degree varies between different provinces and regions, as can be seen in Figure 8, where A2 and A3, with curtailment rates standing at $4.5 \%$ and $5.5 \%$ respectively, are influenced more by load capacity than A5 and A6 whose curtailment rates are $2.7 \%$ and $2.1 \%$ respectively. 
Table 2. Peak-load regulation capability of thermal power.

\begin{tabular}{ccccc}
\hline \multirow{2}{*}{$\begin{array}{c}\text { Capacity of pumping } \\
\text { thermal power } \\
\text { (MW) }\end{array}$} & \multicolumn{2}{c}{ Heating period } & \multicolumn{2}{c}{ Non-heating period } \\
\cline { 2 - 5 } & $\begin{array}{c}\text { Minimum number of } \\
\text { operating unit }\end{array}$ & $\begin{array}{c}\text { Minimum output of } \\
\text { operating unit (\%) }\end{array}$ & $\begin{array}{c}\text { Minimum number of } \\
\text { operating unit }\end{array}$ & $\begin{array}{c}\text { Minimum output of } \\
\text { operating unit (\%) }\end{array}$ \\
\hline 100 & 4 & 75 & 2 & 70 \\
200 & 14 & 64 & 9 & 58 \\
300 & 18 & 69 & 10 & 7 \\
330 & 13 & 67 & 4 & 52 \\
600 & 6 & 50 & & 47 \\
\hline
\end{tabular}

Table 3. Calcuation results of 2013.

\begin{tabular}{ccccc}
\hline $\begin{array}{c}\text { Year of normalization } \\
\text { output sequence of wind } \\
\text { power }\end{array}$ & $\begin{array}{c}\text { Generated energy of } \\
\text { wind power (TWh) }\end{array}$ & $\begin{array}{c}\text { Curtailment energy of } \\
\text { wind power (TWh) }\end{array}$ & $\begin{array}{c}\text { Curtailment ratio of } \\
\text { wind power (\%) }\end{array}$ & $\begin{array}{c}\text { Full load hour of wind } \\
\text { power (h) }\end{array}$ \\
\hline 2010 & 11.78 & 1.73 & 12.8 & 1703 \\
2011 & 11.64 & 1.79 & 13.3 & 1682 \\
2012 & 11.47 & 2.00 & 14.8 & 1658 \\
$\mathbf{2 0 1 3}$ & $\mathbf{1 1 . 7 3}$ & $\mathbf{1 . 8 0}$ & $\mathbf{1 3 . 3}$ & $\mathbf{1 6 9 2}$ \\
2014 & 11.93 & 1.59 & 11.7 & 1725 \\
\hline
\end{tabular}

Table 4. Impact of thermal power peak-load regulation capacity on wind power accommodation.

\begin{tabular}{cccc}
\hline $\begin{array}{c}\text { Spinning capacity } \\
(\%)\end{array}$ & $\begin{array}{c}\text { Electricity generation of wind } \\
\text { power (TWh) }\end{array}$ & $\begin{array}{c}\text { Curtailment of wind power } \\
(\text { TWh })\end{array}$ & $\begin{array}{c}\text { Curtailment ratio of wind } \\
\text { power (\%) }\end{array}$ \\
\hline 5 & 11.23 & 1.82 & 13.96 \\
10 & 11.11 & 1.94 & 14.85 \\
15 & 10.93 & 2.12 & 16.28 \\
20 & 10.60 & 2.45 & 18.77 \\
\hline
\end{tabular}

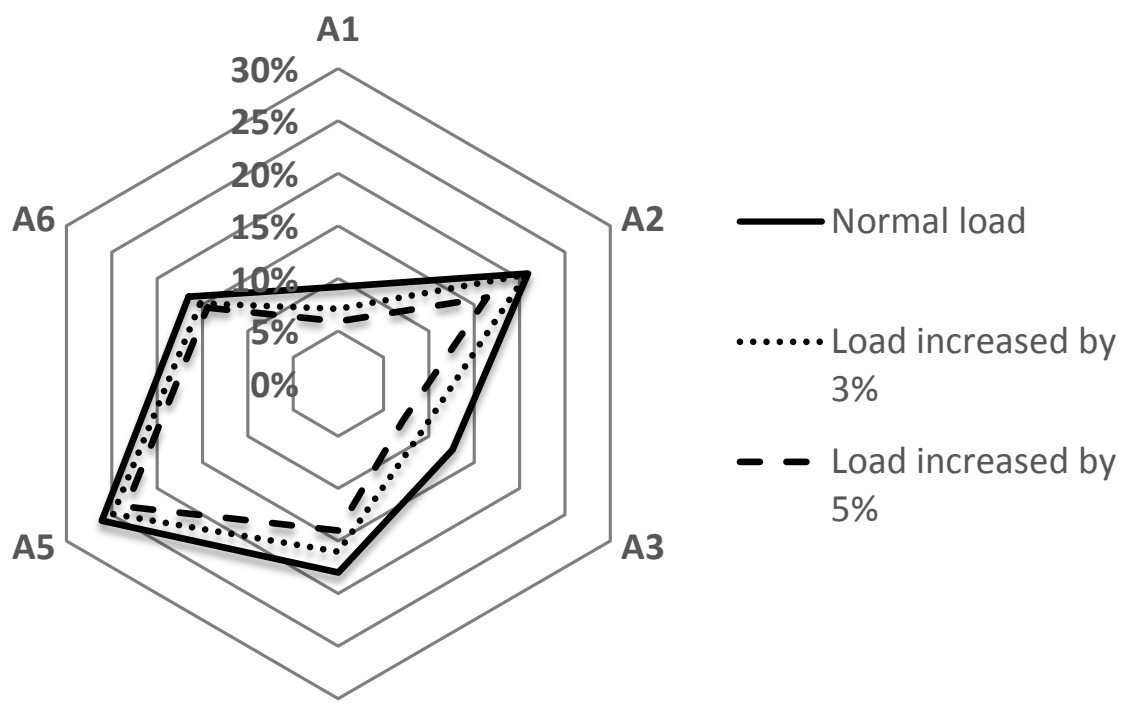

A4

Figure 8. Influence of load capacity on wind power curtailment. 


\section{Conclusion}

This paper establishes the time sequence simulation model with targeted maximum wind power consumption. The impact of unit commitment, peaking capacity of thermal power units and spinning reserve on wind power accommodation has been analyzed. Calculation of specific power grid operation statistics in 2013 verifies the precision of the adopted simulation model. Spinning reserve, wind resources and load capacity have significant impact on wind power curtailment, and the impact of each factor on wind power accommodation varies between different power grids. Calculation results in this paper will provide reference to solving the problem of wind power curtailment.

\section{References}

[1] Liu, C., Lv, Z.H., Huang, Y.H., et al. (2013) A New Method to Simulate Wind Power Time Series of Large Time Scale. Power System Protection and Control, 41, 7-13.

[2] Kang, C.Q., Zhou, T.R., Chen, Q.X., et al. (2009) Assessment Model on Low-Carbon Effects of Power Grid and Its Application. Power System Technology, 33, 1-7.

[3] Ummels, B.C., Gibescu, M. and Pelgrum, E. (2007) Impacts of Wind Power on Thermal Generation Unit Commitment and Dispatch. IEEE Transactions on Energy Conversion, 22, 44-51. http://dx.doi.org/10.1109/TEC.2006.889616

[4] Zhu, L.Z., Chen, N. and Han, H.L. (2011) Key Problems and Solutions of Wind Power Accommodation. Automation of Electric Power Systems, 35, 29-34.

[5] Xue, B., Zhang, X. and Zheng, Y.X. (2014) Influence of Thermal Unit Spinning Reserve on Wind Power Accommodation. East China Electric Power, 42, 1550-1553.

[6] Cao, Y., Li, P. and Yuan, Y. (2014) Analysis on Accommodating Capability of Renewable Energy and Assessment on Low-Carbon Benefits Based on Time Sequence Simulation. Automation of Electric Power Systems, 38, 60-66.

[7] Liu, D.W. and Huang, Y.H. (2011) Research and Enlightenment of High Percentage of Wind Power in Spain. Renewable Energy, 33, 25-28.

[8] Xie, G.H. and Li, Q.H. (2011) Research on Calculating Model and Empirical Analysis of Wind Power Ancillary Service Cost. Electric Power, 44, 82-85. 